\title{
ADOLESCENTES EM CONFLITO COM A LEI NO CONTEXTO DE DESIGUALDADES: UMA ANÁLISE SOBRE A COMUNICAÇÃO E O DIREITO NA SOCIEDADE.
}

\author{
Kátia Simone Azevedo ${ }^{1}$ \\ Gabriela Maia Reboucas ${ }^{2}$
}

\section{RESUMO}

Este artigo explora o tema do adolescente em conflito com a lei a partir da relação entre os meios de comunicação e o direito em um contexto de desigualdades. Enquanto espaço hegemônico de informação e representante de um modelo de desenvolvimento a serviço do consumo e da violência, a mídia nega os direitos humanos ao promover um cenário de violações por meio do qual o sensacionalismo da notícia inviabiliza um projeto social coletivo comprometido com a formação cidadã. Do ponto de vista metodológico, esta pesquisa caracteriza-se como um estudo analítico com levantamento de dados bibliográficos e documentais. Assim, são discutidos os desafios da relação do direito e do jornalismo, fórum onde são travadas tais questões.

PALAVRAS-CHAVE: Direitos Humanos, Comunicação, Adolescentes em conflito com a lei, Desigualdades sociais

\section{ADOLESCENTS IN CONFLICT WITH LAW IN THE CONTEXT OF INEQUALITIES: AN ANALYSIS OF COMMUNICATION AND RIGHT IN SOCIETY}

\begin{abstract}
This article explores the issue of adolescents in conflict with the law from the relationship between the media and the law in the context of inequalities. As a hegemonic space of information and a representative of a development model in the service of consumption and violence, the media denies human rights by promoting a scenario of violations through which the sensationalism of news makes a collective social project compromised with the citizen training. From the methodological point of view, this research is characterized as an analytical study with collection of bibliographical and documentary data. Thus, the challenges of the relationship of law and journalism, a forum where such issues are addressed, are discussed.
\end{abstract}

KEY WORDS: Human rights, Communication, Adolescents in conflict with the law, Social inequalities

\section{INTRODUÇÃO}

A comunicação como espaço de reflexão para o enfrentamento das desigualdades sociais passa a incorporar o debate de uma necessária mudança cultural a partir da prática do

\footnotetext{
${ }^{1}$ Jornalista. Mestre em Direitos Humanos pela Unit/SE.

2 Doutora em Direito (UFPE 2010) com Pós-doutorado CES/Universidade de Coimbra 2015/2016. Professora e Pesquisadora do Mestrado em Direitos Humanos - UNIT/SE e do Mestrado em Sociedade, Tecnologias e Políticas Públicas - UNIT/AL
} 
direito vivenciada na vida social. Neste aspecto, este trabalho problematiza a relação entre direitos humanos e a imprensa, no cenário de violação de direitos por meio do sensacionalismo e espetacularização da notícia a favor de um modelo que inviabiliza a concretização de um projeto social coletivo.

O problema de pesquisa aqui proposto se baseia na análise do discurso midiático como um local no domínio dos direitos humanos, tentando elucidar as ligações entre o fazer jornalístico e as relações de poder que marcam este espaço de comunicação, sobretudo a partir da análise de notícias que tratam de adolescentes envolvidos em atos infracionais.

Para tanto, aqui se defende a hipótese de que os meios de comunicação, como arena política e fórum de debate público, comumente constroem discursos contraditórios e rasos sobre os direitos humanos e, consequentemente, interferem diretamente na visibilidade e aplicação de direitos no ordenamento social. Do ponto de vista metodológico, esta pesquisa caracteriza-se como um estudo analítico com levantamento de dados bibliográficos e documentais.

Tais questões são ressaltadas com o objetivo de discutir a conjuntura teórica dos direitos humanos e da produção histórica destes, avaliando os discursos jornalísticos, para considerar a necessária mudança nos meios de comunicação, imersos em um processo de construção e consolidação de uma cultura arraigada na violência e não-direito no imaginário coletivo.

Nota-se que apesar de muitos avanços, esta questão ainda se coloca como uma das mais desafiadoras, numa conjuntura social de desrespeito e incompreensão da problemática envolvendo crianças e adolescentes, no que concerne ações de enfrentamento à realidade de exclusão social. Neste cenário, se faz importante uma efetiva mudança cultural no campo da comunicação e dos direitos humanos, com a proposta de reverter o quadro de valorização da punição e da negação de direitos. É nesta conjuntura que se pauta o presente trabalho, pensado a partir de uma perspectiva do papel dos meios de comunicação e a sua relação com os direitos humanos.

\section{COMUNICAÇÃO, SENSACIONALISMO E DIREITOS HUMANOS}

A garantia do direito à comunicação democrática e ao acesso à informação para a consolidação de uma cultura de educação em direitos humanos é uma das condições necessárias apontadas pelo relatório de recomendação do Programa Nacional de Direitos 
Humanos (PNDH3), para o efetivo desenvolvimento social e exercício de direitos no Brasil através de políticas públicas nesta área. Tal prerrogativa é considerada um dos desafios a ser enfrentados pela nação brasileira no que diz respeito a promoção e respeito aos direitos humanos nos meios de comunicação, cujo papel é o de promover uma cultura comprometida com esta temática.

Com base na recomendação do PNDH 3, refletir o papel do direito na sociedade numa perspectiva de desenvolvimento em favor das minorias é compreender a função das instituições deomcráticas a exemplo dos meios de comunicação no processo de fortalecimento da cidadania.

A proposta é situar a discussão sobre direitos humanos, jornalismo e adolescentes em conflito a lei a partir de um exemplo midiático de sensacionalismo conhecido na imprensa de Sergipe como "Caso Pipita", empreendido pelo semanário Cinform no ano de 2008 e que é abordado no tópico seguinte.

\section{1 "Caso Pipita"}

Há nove anos, um adolescente, Cleverton Santos Reis, alimentou de forma recorrente o noticiário sergipano, durante os três primeiros meses de 2008, sendo o principal personagem de um acontecimento midiático que ficou conhecido como o "Caso Pipita". O adolescente, com então 17 anos, era acusado pela prática de atos infracionais no município de Tomar do Geru, mas foi a sua sagacidade em escapar do cerco policial que o tornou assunto principal dos veículos de comunicação naquele período. O apelido de infância passou então a ser adotado pela imprensa com o tom estigmatizador de "Pipita", atribuindo-o uma ideia de periculosidade.

A cobertura jornalística sobre o episódio teve, sobretudo, no jornal Cinform ${ }^{3}$, o semanário de classificados mais popular de Sergipe, intensa cobertura em relação ao comportamento violento atribuído ao adolescente, apontado como liderança de grupos de “delinquência juvenil” que aterrorizavam a região centro-sul de Sergipe, onde, segundo o

\footnotetext{
${ }^{3}$ O Cinform tem 35 anos de atuação como único impresso em Sergipe que circula toda segunda-feira, iniciando suas atividades com a publicação de anúncios promocionais e notas de classificados, o que deu origem ao seu nome. Além de Sergipe, também circula nos estados de Alagoas e Bahia, incluindo suas capitais. Sua linha editorial é marcada pela divulgação de escândalos, notícias policiais e problemas urbanos. De acordo com o Instituto Verificador de Circulação (IVC), em dezembro de 2008, ano do caso pesquisado, o veículo registrou um recorde de vendas, com um total anual de 15.898 exemplares.
} 
jornal, o jovem potencializou "[...] suas maldades, permeadas por assaltos, assassinatos, sequestro de menores e excesso de abuso sexual" (Cinform, Edição 1302, Caderno 1, p. 3, 24 a 30 de março de 2008).

Em edições de fevereiro a abril daquele ano, o jornal divulgou massivamente e de forma sensacionalista manchetes e narrativas depreciativas para chamar a atenção da opinião pública em relação ao caso. O cenário de terror e a sensação de insegurança tomaram conta de todo o estado influenciados por manchetes que enunciavam, por exemplo, "Pipita: Estuprador Sanguinário quer matar prefeita e derrubar oito policiais” (Josailto Lima, Cinform, Edição 1299, Caderno 1, Segurança Pública, p,13, 03 a 09 de março de 2008).

O tom punitivista esteve presente em várias narrativas jornalísticas como se vê no seguinte enunciado:

Felizmente os aparelhos da Segurança Pública de Sergipe incorporaram a compreensão de que este marginal Pipita e suas práticas são mesmo um problema clássico de Estado, e estão disponibilizando estratégias e condições para capturá-lo e dar-lhe o destino que ele merece, que é o do cárcere (Cinform, Editoral, edição 1299, 03 a 09 de março de 2008, Segurança Pública, p.13)

Ao longo de sucessivas edições, a exposição midiática do adolescente ocupou as mais diversas seções do jornal, tais como o editorial, a carta ao leitor, a página de cidades e de municípios, tendo como principal assunto as constantes fugas do adolescente durante as operações policiais para sua apreensão. Tamanha visibilidade e repercussão desta cobertura midiática suscita um questionamento se o "Caso Pipita" constituiu mais uma espetacularização da mídia local do que uma real ameaça social como era anunciada pelas notícias sensacionalistas nas quais imperava o clima de pânico e de uma situação fora de controle.

Em linhas gerais, os fatos midiatizados envolvendo as constantes fugas do adolescente terminaram por legitimar a atuação violenta da polícia que passou a ser a principal fonte de informação das notícias. Consequentemente, a situação tornou a cobertura essencialmente policialesca. Aliado a isto, o grande clamor social pela apreensão do jovem favoreceu a disseminação do discurso em favor da violência policial como resposta à criminalidade e à intolerância.

Evidentemente, o discurso que passou a predominar, tanto na esfera midiática quanto na esfera social, reivindicava a morte do adolescente como solução para o problema da insegurança, fato que teve grande aceitação da opinião pública e que ganhou destaque por meio de uma retórica da impunidade e da violência com desdobramentos da violação de 
garantias constitucionais. Findou com a morte do adolescente, e uma manchete grotesca: "Pipita é mandado aos quintos dos infernos!" (Cinform, Edição 1302, primeira página, 24 a 30 de março de 2008).

\subsection{Sensacionalismo e mídia}

Neste contexto, apenas pautando-se por critérios sensacionalistas, o jornal publicou matérias que negligenciaram a condição do adolescente enquanto pessoa em desenvolvimento e o reconhecimento de sua situação de vulnerabilidade ao privilegiar uma cobertura de exposição tanto do jovem quanto das vítimas. Um exemplo disso foi a divulgação do seu nome e de sua imagem, ainda em vida, quando era procurado pela polícia.

Este exemplo reflete violações de direitos por parte dos meios de comunicação, o que sugere uma série de reflexões sobre a atuação do jornalismo na sociedade no que se refere a postura sensacionalista da mídia ao abordar certos temas referentes ao direito e situações de desigualdades sociais como as que expõem jovens à prática infracional. Um desses aspectos é a dimensão espetacularizada da violência e sua relação com a temática da justiça e segurança pública como prática noticiosa. Ao adotarem tal postura, os meios de comunicação favorecem “[...] conteúdos descontextualizados; à troca do essencial pelo supérfluo ou pitoresco e inversão do conteúdo pela forma [...]” (AMARAL, 2006, p. 21), ou ainda produzem um “[...] conteúdo exploratório do espetacular enquanto elemento constitutivo da notícia [...]" (COSTA, 2005, p.6).

Dentro desta lógica, Norma Missae Takeuti defende que a produção de conteúdo midiático, especificamente o gerado pelo jornalismo, é responsável por alimentar um sentimento de insegurança na sociedade e da cultura do medo, fato que está associado ao sensacionalismo adotado no noticiário ao tratar de acontecimentos sobre a violência. Desta forma:

Suas mensagens produzem sobretudo o efeito de insensibilização (anestesia das emoções e dos sentimentos) dos telespectadores/leitores, que passam a ter atitudes de 'indiferença e apatia' diante dos excessos de discursos e imagens de violência. A sucessão de fatos e imagens da violência quotidiana não mais espanta e mobiliza as pessoas pro-ativamente [...] (TAKEUTI, 2002, p.168, destaques da autora)

Nesta direção, a autora associa a espetacularização midiática de casos violentos à necessidade de consumo de notícias no cenário capitalista no qual "[...] a violência tornou-se um produto mercadológico [...]" (TAKEUTI, 2002, p. 168), cujos apelos emocionais e 
estéticos acabaram por substituir na sociedade contemporânea o "[...] caráter informativo, de esclarecimento ao público espectador [...]” (TAKEUTI, 2002, p. 168).

Ao analisar o atual cenário dos processos comunicacionais e a sua relação com a cultura da violência, a autora aponta para o fenômeno de situações sociais que legitimam a prática midiática da exposição de crimes, de seus autores e vítimas no cotidiano, fatos que justificam, segundo Takeuti (2002), o uso da expressão "violência estetizada", marcada por uma ambiguidade "[...] presente nesse modo de vida em que, se, por um lado há medo, desconfiança e isolamento, por outro, há o fascínio diante das imagens reais ou estilizadas dessa violência" (TAKEUTI, 2002, p.168).

Diante do exposto, evidencia-se a necessidade de compreensão dos discursos da mídia situados em relação à violência, tendo em vista o impacto na legitimidade e efetividade dos direitos humanos. Como revela a autora, o tratamento jornalístico dado a esta questão suscita críticas quanto ao papel da imprensa na legitimação de uma sociedade que vivencia e defende a cultura de crenças e valores da punição. Neste contexto, está situada a operacionalização do fazer jornalístico. Nas palavras da autora:

Se há, no Brasil, profissionais dos meios de comunicação orientando-se para um tipo de produção (mais) crítica de informações, não há como negar que um certo tipo de produção da imprensa escrita e televisiva tende a transformar num grande espetáculo os acontecimentos de 'violência' (TAKEUTI, 2002, p. 168, destaque da autora).

Nesta conjuntura da violência midiática espetacularizada situa-se, como aponta a autora, a questão dos jovens como potenciais "suspeitos sociais" (TAKEUTI, 2002, p. 172), estes originados da cultura do medo e alvos de "[...] desconfianças, intolerâncias, exacerbações de atitudes agressivas contra os possíveis 'responsáveis' pelo caso e desordem social" (TAKEUTI, 2002, p. 172, destaque da autora).

Torna-se evidente, a partir desta constatação, o papel privilegiado da mídia na construção social da imagem dos adolescentes autores de ato infracional. De acordo com a autora, “[...] os jovens são os primeiros suspeitos das desordens sociais, e não raras vezes, acusados de serem 'violentos, baderneiros e malfeitores' ” (TAKEUTI, 2002, p.172, destaques da autora). Assim:

Tal representação é reforçada pelas estatísticas que indicam a participação na criminalidade urbana, de segmentos populacionais de faixa etária cada vez mais jovens. Essas evidências imediatas despertam nas pessoas imbuídas pela moral da ordem, a premente necessidade de lançarem-se numa cruzada de combates a mais um mal-estar social da contemporaneidade: a 'violência' dos jovens. Representa-se e identifica-se um sintoma, enfim, bem localizado numa faixa etária específica da população (TAKEUTI, 2002, p.172, destaques da autora). 
Ainda no contexto dessa discussão, a percepção da mídia como prática violadora de direitos prevalece em um discurso punitivo. Dessa forma, Marocco (1998) mostra com base na perspectiva da teoria do filósofo Michel Foucault, como os discursos jornalísticos operam na sociedade como uma nova forma de punição, não mais como um dispositivo de sujeição dos $\operatorname{corpos}^{4}$, mas na "[...] idéia de notícia como um instrumento de exclusão social, graças à objetivação da periculosidade de certos indivíduos" (MAROCCO, 1998, p.10). Conforme a autora:

\begin{abstract}
A notícia [...] insinua-se como instrumento de controle social que pode gerar a coesão social em torno da norma (que marginaliza o outro infrator) ou dar conta dos procedimentos técnicos de coação dos corpos dos mais perigosos, incluindo-os num discurso para viabilizar sua exclusão da sociedade. Neste duplo sentido, isso é, de coesão dos indivíduos em torno da norma e das limitações coercitivas dos corpos sob as técnicas disciplinares, executadas por unia rede de instituições, poder-se-ia explicar a ordem social (MAROCCO, 1998, p.10).
\end{abstract}

Esta perspectiva de compreender o funcionamento da mídia enquanto dispositivo de controle da violência social remete a outras reflexões sobre o papel dos meios de comunicação na construção simbólica das sociedades punitivas. Desta forma “[...] a ação dos meios de comunicação [...] tem conferido aos processos, sobretudo aos seguidos por delitos de particular interesse social, uma ressonância pública que às vezes tem para o réu um caráter aflitivo e punitivo bem mais temível do que as penas" (FERRAJOLI, 2002, p.330).

De outro modo, esta discussão tem relação com o que Frédéric Gros (2001) aponta como centros de sentido da pena, por meio dos quais a sociedade busca respostas lógicas para justificar a aplicação de discursos punitivos. "Punir é defender a sociedade (...) em que o castigável assume as figuras materiais do monstro doente, do inimigo, do pequeno déspota, do enganador e do mal calculador" (GROS, 2001, p. 12-13.)

A principal contribuição deste debate é possibilitar analisar a punição em um sentido social. Neste raciocínio, pode-se incorporar o excesso de punitivismo adotado pela mídia na cobertura jornalística como uma prerrogativa "[...] ao direito social de punir e sua relação entre a sociedade e o Estado" (GROS, 2001, p. 60).

Os efeitos punitivos sob o ponto de vista do papel dos meios de comunicação podem ser discutidos na relação entre a mídia e a "cultura do espetáculo" (GREGOLIN, 2003, p.12). Este debate se faz no campo dos estudos do discurso e dos seus efeitos na produção de sentidos. Nesta perspectiva, a noção de sensacionalismo e suas implicações em práticas sociais estão presentes na afirmação “de que os meios de comunicação constroem

\footnotetext{
${ }^{4}$ Nesta perspectiva, a notícia é entendida como dispositivo sofisticado de punição disciplinar em substituição a dor física que sujeita os corpos ao suplício, mas com mesmo sentido de correção de condutas
} 
discursivamente uma espetacularização dos acontecimentos" (GREGOLIN, 2003, p. 9). Esta ideia parte do entendimento de que a relação entre a mídia e a espetacularização da cultura origina um espaço de "[...] batalhas movendo a construção dos sentidos na sociedade" (GREGOLIN, 2003, p. 12) na construção da realidade social, hipermidiatizada, não problematizada, e movida pelo espetáculo grotesco.

Para problematizar esta questão, é preciso considerar ainda a discussão acerca das relações de experiências sociais que os meios de comunicações podem construir a partir de uma mudança de atuação que favoreça os valores dos direitos humanos. Como afirma Gilberto Velho, “[...] a temática da violência pode ser um caso exemplar na reelaboração de toda a concepção hoje vigente sobre a televisão e comunicação de massas" (VELHO, 2002, p. 67). Trata-se, portanto, de reconhecer a possibilidade de mudanças na prática discursiva midiática, e, consequentemente, na prática social.

Nesta perspectiva, contribuições do campo da teoria crítica dos direitos humanos são relevantes, favorecendo uma reflexão não somente do ponto de vista do cenário das violações pragmáticas e sistematicamente produzidas e reproduzidas pela imprensa, mas, além disso, buscando alternativas para uma possível transformação desta realidade. Algumas reflexões apresentadas por Cecília Coimbra inserem-se neste contexto, uma vez que a autora trata da criminalização da pobreza e sua relação com a dimensão dos direitos humanos, ressaltando que a construção da ideia de perigo e ameaça social sempre esteve associada a uma forma de controle na formação dos sujeitos. Como afirma Coimbra (2006), “[...] desde o final do século XIX, já se encontravam presentes nas elites brasileiras as subjetividades que constituem o dispositivo da periculosidade. Dispositivo este, apontado por Foucault (1996), que emerge com a sociedade disciplinar [...]" (COIMBRA, 2006, p.2).

Desta forma, a autora empreende uma crítica à constituição de um saber acerca das "classes perigosas" adotado como discurso hegemônico ao longo da história e consolidada na sociedade atual por instituições detentoras do conhecimento como a medicina e a justiça, o que também inclui os meios de comunicação utilizados como espaços produtores de informação jornalística que validam fatos cotidianos como verdadeiros, sendo também um dispositivo discursivo de controle social. Portanto:

Presente entre nós até os dias de hoje, esse dispositivo vai afirmar que tão importante quanto o que um indivíduo fez, é o que ele poderá vir a fazer. É o controle das virtualidades; importante e eficaz instrumento de desqualificação e menorização que institui certas essências, certas identidades. Afirma -se, então, que dependendo de uma certa natureza (pobre, negro, semi-alfabetizado, morador de periferia, etc etc etc) poder-se-á vir a cometer atos perigosos, poder-se-á entrar para o caminho da criminalidade (COIMBRA, 2006, p.2 e 3, destaque nosso). 
Neste contexto de violações também é clara a representação midiática de discursos que cumprem o papel de disseminação da violência e da negação dos direitos que passam a ser legitimados socialmente. Neste raciocínio, o conceito de Marilena Chauí sobre o discurso competente pode ser aplicado à atuação da mídia. Conforme a autora "o discurso competente é aquele que pode ser ouvido e aceito como verdadeiro ou autorizado (estes termos agora se equivalem) porque perdeu os laços com o lugar e o tempo de sua origem" (CHAUÍ, 2011, p.19).

Como observado neste tópico, é possível compreender o contexto de exclusão social e da violência juvenil e sua relação com a produção de identidades do adolescente em conflito com a lei. A estas questões, somam-se outras como o papel dos meios de comunicação na dimensão midiática da violência e o discurso punitivo da imprensa percebida aqui como uma reconfiguração de violações aos direitos humanos no contexto de produção de identidades de jovens autores de ato infracional.

\section{DIREITOS HUMANOS E OS DESAFIOS DA EXPERIÊNCIA EMANCIPADORA}

Dada a importância da comunicação midiática como um dos elementos para a formação da opinião pública acerca dos direitos humanos, despontando como fórum de circulação dos mais diversos discursos relacionados, alguns enfoques teóricos se mostram mais relevantes. Privilegia-se, portanto, aqueles que consideram que os direitos humanos nascem de um arranjo de forças que tem na esfera política seu componente desafiador e nos meios de comunicação o seu espaço de interlocução, passível de gerir o diálogo e o agendamento público desta questão, de modo a provocar a superação dos desafios éticos que se impõem.

Entretanto, considerando os desafios da comunicação no contexto de violações de direitos e entendendo a mídia como espaço legítimo de disputa e de poder, os veículos midiáticos circulam discursos hegemônicos e contra hegemônicos (usualmente de forma assimétrica), ora demarcados pela defesa dos direitos humanos, ora contra, desprezando-os e subjugando-os.

Nesta ordem, a ação midiática espetacularizada ressalta a importante discussão sobre os desafios impostos no cenário da comunicação jornalística em relação aos direitos humanos. Portanto, pensar a relação entre comunicação e direitos humanos, sobretudo a partir da teoria 
crítica, orienta a busca por novas perspectivas nas quais as práticas sociais emancipatórias sejam incorporadas às experiências cotidianas para a promoção de uma nova cultura de fortalecimento da luta pela dignidade, uma reflexão necessária nos contextos desafiadores que se apresentam.

Tal debate é oportuno, considerando que os meios de comunicação estão situados, história e culturalmente no cenário de embates discursivos nos quais, no contexto específico deste trabalho, os direitos humanos constroem um diálogo plural, através de tensões inevitáveis e de paradoxos que contradizem princípios elementares de igualdade, cidadania e justiça. Esta discussão recai sobre a problematização acerca dos direitos humanos como naturais, como relacionados com práticas cotidianas de violações dos mais diferentes direitos enquanto valores e princípios eternos, a-históricos, universais e naturais. Assim, dada a vasta dimensão dos direitos humanos, estes acabam sendo incorporados na sociedade muitas vezes de forma equivocada pela mídia como objeto de debate público, sujeitos a críticas que muitas vezes não fortalecem a democracia.

Nesta perspectiva, Grandinetti Castanho de Carvalho considera que a imprensa é guardiã de valores democráticos que representam importantes instrumentos de efetivação de direitos. Sobre isso, o autor salienta que:

\footnotetext{
A imprensa é o termômetro da democracia. Quanto mais livre um povo, mais livre a sua imprensa; quanto mais educado e evoluído, mais responsável e socialmente útil é a sua imprensa. Daí poder-se dizer, também, que a imprensa é o termômetro do grau de cultura e maturidade de um povo (GRANDINETTI CASTANHO DE CARVALHO, 2003, p. 3).
}

Nesta conjuntura, a teoria crítica dos direitos humanos oferece importantes contribuições. Ao propor uma perspectiva contextualizada em práticas sociais emancipadoras, Joaquín Herrera Flores, afirma que “[...] os direitos humanos não são conquistados apenas por meio das normas jurídicas que propiciam seu reconhecimento, mas também, e por modo muito especial, por meio das práticas sociais" (HERRERA FLORES, 2009, p. 77). Nesta perspectiva emancipadora defendida por Joaquín Herrera Flores, os direitos humanos são práticas sociais concretas e "[..] criados e recriados na medida em que vamos atuando no processo de construção social da realidade" (HERRERA FLORES, 2009, p. 79).

Ao situar a questão dos direitos humanos como o maior desafio do século XXI, o autor propõe uma reflexão das complexidades conjunturais dos conflitos sociais que marcam o processo de reinvenção de tais direitos, pensados a partir de uma nova cultura, com respeito à pluralidade e à diversidade e como instrumento de fortalecimento de espaços de lutas sociais 
pela dignidade humana. Reconhece, portanto, que "para construir uma teoria crítica e complexa dos direitos, necessitamos de outra forma de entender a ação social" (HERRERA FLORES, 2009, p.81).

Do mesmo modo, a proposta da ação emancipadora aponta para os desafios impostos pela sociedade contemporânea no que concerne o modo de vida em um cenário capitalista de experiências humanas fragilizadas. Assim:

\begin{abstract}
A globalização da racionalidade capitalista supõe a globalização de uma ideologia baseada no individualismo competitivo e exploração. Essa constatação nos obriga a todos que estamos comprometidos com uma visão crítica e emancipadora dos direitos humanos a contrapor outro tipo de racionalidade mais atenta aos desejos e às necessidades humanas que às expectativas de benefício imediato do capital. Os direitos humanos podem se converter em uma pauta jurídica, ética e social que sirva de guia para a construção dessa nova racionalidade (HERRERA FLORES, 2009, p. 23).
\end{abstract}

Neste cenário, ainda de acordo com Joaquín Herrera Flores, os direitos humanos são entendidos como processo no qual as práticas sociais e a revisão conceitual dos mesmos devem viabilizar as mudanças necessárias para a efetivação de garantias de direitos, condição imprescindível para o rompimento de processos de formação ideológica e econômica que comprometem a prática de tais direitos. Ressaltando duas concepções acerca dos direitos humanos, o autor destaca:

Clássica e tradicionalmente considerados como parte da essência humana, os direitos humanos são reduzidos, por um lado, à mera retórica conservadora - ou evangelizadora - que serve mais para justificar o injustificável que para resolver os problemas concretos da humanidade. Por outro lado, são concebidos como uma proposta utópica dirigida a vingar os povos das maldades de ditadores e golpistas absolutamente funcionais ao novo totalitarismo de mercado absoluto e onisciente (HERRERA FLORES, 2009, p. 26).

A partir do pensamento de Herrera Flores (2009), os direitos humanos podem ser percebidos simultaneamente como uma construção social e também no exercício de um papel de embate para a efetividade e o surgimento de novos direitos, adquirindo assim um caráter dinâmico na sociedade. Assim:

Os direitos humanos são uma convenção cultural que utilizamos para introduzir uma tensão entre os direitos reconhecidos e as práticas sociais que buscam tanto seu reconhecimento como positivado como outra forma de reconhecimento ou outro procedimento que garanta algo que é, ao mesmo tempo, exterior e interior a tais normas (HERRERAS FLORES, 2009, p. 34)

Do mesmo modo, para Boaventura de Sousa Santos (2011), os direitos humanos, enquanto prática social, representam um espaço de embate em resposta ao projeto da sociedade capitalista que suprimiu direitos, o que na visão do autor, tornou a concretização de tais direitos em um processo ainda irrealizável nos contextos da ordem social contemporânea. 
Deste modo, o autor reconhece que "não parece que faltem no mundo de hoje situações ou condições que nos suscitem desconforto ou indignação e nos produzam inconformismo. Basta rever até que ponto as grandes promessas da modernidade permanecem incumpridas" (SOUSA SANTOS, 2011, p. 23).

Assim, ao tratar das tensões da modernidade ocidental como desafios de efetividade dos direitos humanos, Boaventura de Sousa Santos (2010) enfatiza a importância de projetos de emancipação como resposta às fragilidades que se impõem no campo de lutas para garantia de direitos. Nesta tensão:

Em todo o mundo os processos hegemônicos de exclusão estão a ser enfrentados por diversas formas de resistência - iniciativas populares de organizações locais, particuladas com redes de solidariedade transnacional - que reagem contra a exclusão social, abrindo espaço para a participação democrática, para a construção da comunidade, para alternativas e formas dominantes de desenvolvimento e de conhecimento, em suma, para novas formas de inclusão social (SOUSA SANTOS, 2010, p. 195 e 196).

O que ganha centralidade neste contexto, é o fato de que estes direitos não podem ser pensados como naturais, mas como conquistas históricas e sociais, em um contínuo processo de construção e reconstrução, portanto, inacabado. Como bem enfatiza Sousa Santos (1989), a historicidade dos direitos humanos acompanha o próprio desenvolvimento do capitalismo: no primeiro momento, do capitalismo liberal, durante todo o século XIX, se verifica a expansão e a consolidação dos direitos civis e políticos; no segundo momento, caracterizado pelo capitalismo organizado e pelo Estado-Providência, as conquistas recaem sobre os direitos sociais e econômicos; e por último, o terceiro momento, o período do capitalismo desorganizado, que se inicia por volta da década de 70 do século XX e se estende até os dias atuais, põe em causa os direitos conquistados anteriormente, mas também é marcado pela luta de direitos pós-materialistas, culturais e de cunho identitário de modos de vida alternativos (feministas, antirracistas, ecológicos etc.).

Neste sentido, Boaventura de Sousa Santos sinaliza que estas conquistas no domínio dos direitos humanos estavam subordinadas às exigências do desenvolvimento do capitalismo nos países centrais, gerando formas específicas de desigualdade. Nas suas palavras:

As lutas pelos direitos humanos no período do capitalismo liberal visaram confrontar e democratizar, na medida do possível, a forma política das relações sociais capitalistas, isto é, a dominação. As lutas do período do capitalismo organizado tiveram como alvo privilegiado a forma social e econômica destas relações e, portanto, a exploração. Por último, as lutas do período do capitalismo desorganizado têm vindo a incidir prevalentemente na dimensão simbólico-cultural das desigualdades, isto é, na alienação. O valor democrático dominante por detrás das lutas sociais pelos direitos humanos foi, no primeiro período, a liberdade, no 
segundo, a igualdade e no terceiro, a autonomia e subjectividade (SOUSA SANTOS, 1989, p. 05).

Também numa perspectiva crítica, Hélio Gallardo analisa a efetividade prática dos direitos humanos nas sociedades modernas. Enquanto resultados das relações sociais e de valores e ideologias “[...] os direitos humanos são produzidos e sustentados pelos seres humanos em sua histórica econômica, sexual, política e espiritual, portanto, podem ser violados, revertidos e anulados por práticas de poder legais ou ilegais" (GALLARDO, 2014, p.11). Nesta perspectiva, “[...] construir uma cultura de direitos humanos exige, assim, um esforço político permanente, uma vez que não podem ser derivados de nenhuma condição inata ou da inércia das instituições" (GALLARDO, 2014, p. 11). Assinala-se, portanto, o papel crucial da mídia neste contexto.

Diante das sinalizações apresentadas anteriormente, e das conjunturas de violações na sociedade contemporânea, os meios de comunicação podem ser pensados tanto como entrave para a afirmação de direitos e valores de cidadania e justiça quanto ferramentas mobilizadoras para a concretização de garantias democráticas. Nesta segunda perspectiva, a atuação midiática pode funcionar como instrumento de educação e direitos humanos, atuando como espaço de legitimação de mudanças sociais. Deste modo:

A compreensão acerca dos direitos humanos é imprescindível e precisa ser capaz de afastar sua equivocada representação, diuturnamente reforçada pelos meios de comunicação de massa, calcada no senso comum, no sentido de que 'defender direitos humanos é defender bandido'. É esse mesmo imaginário que sustenta a defesa de penas mais duras e a tese da necessidade de restrição de direitos no campo processual-penal, sendo a partir daí que propostas como o programa de tolerância zero se estabeleça. Para romper com esse imaginário, é preciso politizar a discussão, criar espaços para veicular idéias, para um contradiscurso diante dessas imagens (REGINATO, 2004, p. 115, destaques da autora).

Analisando a atuação dos meios de comunicação na perspectiva de defesa de direitos, é possível contextualizar esta questão a partir da Teoria Social da Mídia através da qual Thompson (1998) identifica o papel da comunicação de massa na formação das sociedades modernas, modificando a interação entre os indivíduos. O autor afirma que "[...] a produção, o armazenamento e a circulação da informação e conteúdo simbólico têm sido aspectos centrais da vida social" (THOMPSON, 1998, p.19). Neste contexto:

O desenvolvimento dos meios de comunicação é, em sentido fundamental, uma reelaboração do caráter simbólico da vida social, uma reorganização dos meios pelos quais a informação e o conteúdo simbólico são produzidos e intercambiados no mundo social e uma reestruturação dos meios pelos quais os indivíduos se relacionam entre si (THOMPSON, 1998, p. 19). 
Neste processo, o autor identifica o poder cultural e simbólico dos meios de comunicação de massa, que se inserem, neste contexto, como uma "[...] atividade de produção, transmissão e recepção do significado das formas simbólicas" (THOMPSON, 1998, p.24). Vista dessa maneira, a comunicação midiática, como proposta pela teoria social de Thompson, é um instrumento de mobilização cultural “[...] de ações simbólicas que podem provocar reações, liderar respostas de determinado teor, sugerir caminhos e decisões, induzir a crer e as descrer, apoiar os negócios do estado ou sublevar as massas em revolta coletiva" (THOMPSON, 1998, p. 24).

Evidencia-se nesta percepção o papel da mídia como poder simbólico. Nas palavras de Thompson, uma ação diretamente ligada à “[...] capacidade de intervir no curso dos acontecimentos, de influenciar as ações dos outros e produzir eventos por meio da produção e da transmissão de formas simbólicas" (THOMPSON, 1998, p.24).

Assim, a comunicação midiática também pode produzir valores culturais que legitimem direitos, sendo uma alternativa dentro da perspectiva de experiência emancipatória diante dos discursos midiáticos e hegemônicos da violência através dos quais se constroem realidades controversas em nome de uma pretensa defesa de justiça. Contudo, os desafios persistem.

Ao tratar do tema dos meios de comunicação e da insegurança social na sociedade globalizada, Lola Aniyar de Castro aborda o tratamento da mídia em relação ao delito em um cenário marcado pela diversidade de valores e conflitos nem sempre conciliáveis sob o ponto de vista dos direitos humanos. Afirma a autora que:

\footnotetext{
A globalização comunicacional incorpora modelos diante do 'diferente' que na Europa e também em muitos dos nossos países, é representado pela figura do imigrante, novo estereótipo de elemento perigoso, visto como delinquente nas representações sociais, políticas e jurisdicionais (CASTRO, 2005, p. 14, destaque da autora).
}

A mídia é discutida pela autora como espaço hegemônico e criminalizador das classes construídas historicamente como marginalizadas, sendo estas últimas excluídas de processos de discussões e representadas por uma lógica imperativa da insegurança social caracterizada pela propagação do medo e do perigo associados a delitos, o que reforça a discussão iniciada anteriormente, acerca do sensacionalismo e da espetacularização.

Pensada desta forma, a experiência da insegurança na comunicação no contexto atual é vista pela autora como uma forma de controle social através da informação, com permanente 
vigilância da opinião pública e do imaginário coletivo das massas. Portanto, a insegurança é, segundo a autora:

Uma situação real de desproteção, do qual às vezes os cidadãos não têm consciência e não chega a configurar um 'sentimento de insegurança'. Ademais, esse 'sentimento de insegurança' pode ter níveis puramente imaginários de medo que um cidadão pode sentir-se inseguro quando não está, e vice-versa (CASTRO, 2005, p. 203, destaques da autora).

Esta ideia de insegurança no imaginário coletivo está associada às questões de comportamentos sociais impostos pelos meios de comunicação na divulgação de assuntos que propagam o medo a partir de situações de atos infracionais praticados por adolescentes. A dimensão dessa realidade é trabalhada a partir da conjuntura histórica na qual o espaço de exclusão social na infância e adolescência pobre no Brasil tem sido sustentada pela noção de perigo e construção de identidades definidas em torno da construção simbólica de ameaça social.

Nesta direção, o enfrentamento de estigmas e de outras formas de violações midiáticas é a tônica das discussões de determinadas posturas profissionais de comunicação diante do desafio de concretização dos direitos humanos por meio de uma cultura social que dialogue com os preceitos da dignidade humana, mas ainda negligenciados pelo discurso punitivo, então hegemônico.

\section{CONSIDERAÇÕES FINAIS}

Este artigo procurou analisar os direitos humanos e a comunicação numa perspectiva crítica do ponto de vista do desenvolvimento baseado na proteção dos direitos das minorias e ações de mobilizações de cidadania.

Com base nas teorias aqui trabalhadas, foi possível verificar a existência de desafios impostos pelo cenário de violações midiáticas presentes em abordagens sensacionalistas nas quais o debate social sobre direito e cidadania comumente são negados. Neste ponto, foram percebidas também as implicações da relação entre a mídia e a efetividade de direitos no contexto de uma realidade perversa de desigualdades sociais e de projetos midiáticos que se fundam e se destinam sobretudo a atender interesses particulares. Isto se encaminha à elaboração de discursos que circulam na sociedade e que tem nas instituições sociais a sua principal aliada, como é o caso dos meios de comunicação. 
Este cenário possibilita reflexões sobre os direitos humanos e a sua relação com os meios de comunicação. Assim, o tema aqui tratado revela a importância de um debate necessário sobre a construção das notícias como elemento integrante da organização do ordenamento social. Um dos principais pontos postos em evidência neste estudo, e que reforça o que se apresenta em nível nacional, é a frágil relação dos meios de comunicação com os direitos humanos, e que, com efeito, é possível arriscar que é resultado da sua deformada visão em relação à democracia e à cidadania.

Portanto, partindo da compreensão do poder social dos meios de comunicação e da sua ingerência na vida social e no domínio da opinião pública, este estudo revela-se pertinente ao dar visibilidade a uma realidade de violação de direitos, passível de constatação ao observar a importância da formação de opinião da mídia, como parte importante para a construção das sociedades.

Por todas as informações relevantes aqui expostas, este trabalho aponta para a necessidade de uma mudança por parte dos meios de comunicação de forma a assegurar os direitos humanos dentro de uma agenda de desenvolvimento que prime pela cidadania e promova uma cultura de respeito à dignidade. Pensar nestas questões é refletir o papel dos meios de comunicação, sobretudo no contexto da cobertura jornalística, no complexo cenário de luta pelos direitos humanos na sociedade, o que exige uma discussão que amplie o debate sobre possibilidades de mudanças, corrigindo, assim, as lacunas que marcam o discurso jornalístico sobre este assunto, por vezes impregnado de uma visão cruel que nega direitos.

\section{REFERÊNCIAS}

AMARAL, Márcia Franz. Jornalismo Popular. São Paulo: Contexto, 2006.

CHAUÍ, Mariela. Cultura e Democracia: O Discurso Competente e Outras Falas. 13a . São Paulo. Côrtez, 2011.

COIMBRA, Cecília, Maria Bouças. Direitos Humanos e Crimanização da Pobreza. Trabalho apresentado em Mesa Redonda: Direitos Humanos e Criminalização da Pobreza no I Seminário Internacional de Direitos Humanos, Violência e Pobreza: a situação de crianças e adolescentes na América Latina hoje, realizado pela UERJ, em outubro de 2006. Disponível em

http://www.slab.uff.br/images/Aqruivos/textos_sti/Cec\%C3\%ADlia\%20Coimbra/texto54.pdf. Consultado em 02 de Fevereiro de 2017

COSTA, Belarmino Cesar Guimarães. Estética da Violência: Jornalismo e Produção de Sentidos. Piracicaba. UNIMEP, 2005 
FERRAJOLI, Luigi. Direito e Razão: Teoria do Garantismo Penal, $3^{\text {a }}$ ed. Vários. Tradutores. Ed. Revista dos Tribunais. 2002.

GALlARDO, Hélio. Teoria Crítica: Matriz e Possibilidades de Direitos Humanos. Tradução de Patrícia Fernandes. Unesp. São Paulo, 2014.

GRANDINETTI CASTANHO DE CARVALHO, Luís Gustavo. Liberdade de Informação e o Direito Difuso à Informação verdadeira. 2a edição. Rio de Janeiro. Renovar, 2003.

GREGOLIN, Maria do Rosário. A mídia e a espetacularização da cultura. IN: Discurso e Mídia: a cultura do espetáculo. Maria do Rosário Valencise Gregolin (org). São Carlos. Claraluz, 2003 (coleção olhares oblíquos)

GROS, Frédéric . Os quatro sentidos da Pena. In: GARAPON, Antoine; GROS, Frédéric e PECH, Thierry. Punir em Democracia e a Justiça Será. Lisboa. Instituto Piachet. 2001. p. 15 a 109.vol.

HERRERA FLORES, Joaquín. A (re) invenção dos Direitos Humanos. Tradução de Carlos Alberto Diogo Garcia, Antônio Henrique Graciano Suxberger e Jeferson, Aparecido Dias. Florianopólis. Fundação Boiteux, 2009.

LIMA, Jozailto. Pipita: Estuprador sanguinário quer matar prefeita e derrubar oito policiais. Jornal Cinform, Aracaju. Ano XXV, Edição 1299, 03 a 09 de Março e 2008, Segurança Pública, Caderno 1, p.13.

MAROCCO, B.A. O espaço perceptivo da exclusão social na mídia. In: Congresso Alaic. Anais. Recife, 1998

PIPITA DEIXA UMA REFLEXÃO AO ESTADO. Jornal Cinform. Aracaju, Ano XXV, Edição 1302, 24 a 30 de Março de 2008, Segurança Pública, Caderno 1, p.3

PIPITA É MANDADO AOS QUINTOS DOS INFERNOS. Jornal Cinform, Aracaju. Ano XXV, Edição 1302, 24 a 30 de Março de 2008, primeira página

REGINATO, Andréia Depiere de Albuquerque. Educação em Direitos Humanos e Polícia: Pensando Novas Perspectivas. In: Educação, Violência e Polícia: Direitos Humanos? FILHO, Manoel Mendonça (org), UFS, 2004.

SOUSA SANTOS, Boaventura. Os Direitos Humanos na Pós-Modernidade. CES, Junho de 1989. Disponível em: http://www.ces.uc.pt/myces/UserFiles/livros/1097_Oficina\%20do\%20CES_10.pdf. Acesso em 10 de setembro de 2014

A gramática do tempo: para uma nova cultura política. São Paulo: Cortez Editora, 2010. p. 433-470.

.A Crítica da Razão Indolente: Contra o desperdício da experiência, 8.ed. São Paulo, Cortez, 2011.

TAKEUTI, Norma Missae. No outro lado do espelho. A fratura social e as pulsões juvenis. Rio de Janeiro: Relume Dumará, 2002. 
THOMPSON, John B. A Mídia e Modernidade: Uma Teoria Social da Mídia. Vozes, 1998 